\title{
Fibre type changes in striated muscle of alcoholics
}

\author{
A HANid, G SLAVin, W MAIR, C SOWTER, P WARD, J WEBB, J LEVI \\ From Northwick Park Hospital \& Clinical Research Centre, Harrow, Middlesex
}

SUMMARY Striated muscle from patients taking more than $80 \mathrm{~g}$ of alcohol each day shows selective atrophy of the type II fibres which are dependent on glycogenolytic pathways. This atrophy is associated with an excess of glycogen and lipid within the fibres and may represent a selective metabolic insult.

Muscle disease in alcoholic patients may take several clinically overt forms with a different onset, severity and course. ${ }^{1}$ Acute myopathy may present with muscular cramps and weakness, rhabdomyolysis and myoglobinuria; chronic myopathy is characterised by weakness and proximal wasting. However, such clinically evident manifestations are uncommon and evidence of subclinical muscle disease may be provided by raised serum activities of muscle enzymes. These clinical and biochemical changes are accompanied by a variety of minor and inconstant changes using standard histological techniques. Kiessling et al. ${ }^{2}$ studied chronic alcoholics and noted a diminution of "fast twitch fibre type size" in those admitted to hospital because of severe alcohol abuse. In this preliminary study we have undertaken the investigation of muscle morphology and function in a group of unselected alcoholics who presented to Northwick Park Hospital and who were drinking heavily at the time of presentation.

\section{Material and methods}

\section{CLINICAL AND BIOCHEMICAL}

Fifteen patients ( 10 male and 5 female) were studied. Each patient admitted to an ethanol intake of more than $80 \mathrm{~g} /$ day. Physical examination included clinical assessment of muscle wasting and weakness. Biochemical estimations included routine liver function tests and serum creatine phosphokinase activities. Each patient had a liver biopsy after admission.

\section{LIGHT MICROSCOPY}

Muscle biopsies were obtained by percutaneous biopsies of vastus lateralis. Using a modified Bergström needle ( $3 \mathrm{~mm}$ diameter) the vastus lateralis was

Accepted for publication 4 March 1981 biopsied at a standard site from the mid-thigh under local analgesia through an incision in the skin and deep fascia. Specimens were allowed to relax in air at room temperature for $15 \mathrm{~min}$ before snap-freezing in isopentane. Cryostat sections were cut with the muscle orientated for cross sections, and stained with a variety of stains including haematoxylin and eosin, ATP-ase at pH 9.4, NAD diaphorase, periodic-acid Schiff, phosphorylase, Oil Red $O$ and Masson's trichrome. Control muscle biopsies were obtained from healthy, non-alcoholic volunteers ( 7 male and 5 female) amongst the staff of this hospital.

\section{ELECTRON MICROSCOPY}

For electron microscopy, the biopsies were stretched on pieces of cork between stainless steel pins and fixed for 15 to $20 \mathrm{~min}$ in $2.5 \%$ glutaraldehyde in $\mathrm{pH}$ $7 \cdot 4,0.1 M$ phosphate buffer containing $2 \mathrm{mM}$ magnesium chloride. Small pieces were then dissected and fixation was continued overnight. The tissue was washed in the phosphate buffer containing $\mathrm{MgCl}_{2}$ and after postfixation in $1 \%$ osmium tetroxide in pH $7 \cdot 4,0 \cdot 1 M$ phosphate buffer they were embedded in araldite or epon. Silver to gold sections were cut and stained with aqueous uranyl acetate and lead citrate.

\section{MORPHOMETRY}

The ATP-ase preparations were examined on a "Magiscan" image analysis system and the fibre diameters of the type I and type II fibres calculated using an interactive computer programme (Slavin and Sowter, unpublished observations) and measuring "fibre diameter" as the maximum distance across the lesser aspect of the fibre. Weighted atrophy and hypertrophy factors were calculated for each fibre type. ${ }^{3}$

Statistics. Changes in the median fibre diameters of 
Table 1 Clinical, laboratory, and histological data in alcoholic patients

\begin{tabular}{|c|c|c|c|c|c|c|c|c|c|c|c|c|}
\hline \multirow[t]{3}{*}{ Patient No } & \multirow[t]{3}{*}{ Sex } & \multirow[t]{3}{*}{ Age (yr) } & \multirow[t]{3}{*}{$A S T$} & \multirow[t]{3}{*}{$G G T P$} & \multirow[t]{3}{*}{$C P K$} & \multirow[t]{3}{*}{$\begin{array}{l}\text { Muscle } \\
\text { wasting }\end{array}$} & \multirow[t]{3}{*}{$\begin{array}{l}\text { Muscle } \\
\text { weakness }\end{array}$} & \multicolumn{2}{|c|}{ Atrophy factor } & \multirow{2}{*}{\multicolumn{2}{|c|}{$\begin{array}{l}\text { Median diameter } \\
(: \alpha m)\end{array}$}} & \multirow[t]{3}{*}{ Liver histology } \\
\hline & & & & & & & & \multirow{2}{*}{ Type I } & \multirow{2}{*}{ Type II } & & & \\
\hline & & & & & & & & & & Type I & Type II & \\
\hline 1 & $\mathbf{F}$ & 56 & 151 & 389 & 90 & Moderate & Yes & 25 & 643 & $55 \cdot 3$ & $29 \cdot 3$ & Gross fatty change \\
\hline 6 & $\mathbf{M}$ & 55 & 467 & 535 & 286 & Minimal & Yes & 320 & 440 & $44 \cdot 6$ & $31 \cdot 9$ & Fatty change \\
\hline 7 & $\mathbf{M}$ & 55 & 66 & 321 & 93 & Moderate & Yes & 193 & 771 & $50 \cdot 7$ & $42 \cdot 7$ & Cirrhosis \\
\hline 2 & $\mathbf{F}$ & 52 & 87 & - & 43 & Marked & Yes & 0 & 234 & $60 \cdot 3$ & $41 \cdot 7$ & Moderate fatty change \\
\hline 3 & $\mathrm{~F}$ & 41 & 94 & 2046 & 31 & Moderate & No & 66 & 735 & $43 \cdot 6$ & $23 \cdot 7$ & Cirrhosis \\
\hline 8 & $\mathbf{M}$ & 45 & 41 & 908 & 55 & Moderate & Yes & 145 & 575 & $52 \cdot 2$ & $42 \cdot 3$ & Moderate fatty change \\
\hline 4 & $\mathbf{F}$ & 55 & 46 & 616 & 113 & Marked & Yes & 40 & 1582 & $47 \cdot 0$ & $17 \cdot 9$ & Moderate fatty change \\
\hline 9 & $\mathbf{M}$ & 49 & 73 & 77 & 145 & Minimal & No & 233 & 193 & $47 \cdot 1$ & $48 \cdot 3$ & Marked fatty change \\
\hline 5 & $\mathbf{F}$ & 57 & 101 & 106 & 57 & Moderate & Yes & 17 & 268 & $57 \cdot 7$ & $39 \cdot 4$ & Cirrhosis \\
\hline 10 & $\mathbf{M}$ & 72 & 39 & 116 & 241 & Minimal & No & 17 & 354 & $64 \cdot 0$ & $52 \cdot 4$ & Mild fatty change \\
\hline 11 & $\mathbf{M}$ & 32 & 32 & 165 & 95 & None & No & 22 & 13 & $59 \cdot 0$ & $65 \cdot 1$ & Mild fatty change \\
\hline 12 & $\mathbf{M}$ & 52 & 53 & 96 & 89 & None & No & 72 & 260 & $55 \cdot 1$ & $51 \cdot 4$ & Mild fatty change \\
\hline 13 & $\mathbf{M}$ & 54 & 19 & 46 & 72 & Minimal & No & 13 & 226 & $58 \cdot 2$ & $49 \cdot 4$ & Mild fatty change \\
\hline 14 & $\mathbf{M}$ & 52 & 47 & - & 68 & None & No & 80 & 211 & $60 \cdot 5$ & $50 \cdot 9$ & Marked fatty change \\
\hline 15 & $\mathbf{M}$ & 64 & 93 & 161 & 51 & None & No & 6 & 233 & $64 \cdot 8$ & $53 \cdot 0$ & Cirrhosis \\
\hline
\end{tabular}

AST $=$ aspartate aminotransferase (normal 0-35 IU/1).

GGTP = gamma-glutamyl transpeptidase (normal 0-50 IU/I).

CPK : creatinine kinase (normal 0-175 IU/1).

Table 2 Median values of fibre diameters in normal adult controls $(\mu \mathrm{m})$

\begin{tabular}{llll}
\hline $\begin{array}{l}\text { Type I fibres } \\
\text { Controls }\end{array}$ & & \multicolumn{2}{l}{$\begin{array}{l}\text { Type II fibres } \\
\text { Controls }\end{array}$} \\
\hline Male & Female & Male & Female \\
\hline 46.5 & 50.3 & 58 & 52 \\
55.1 & 51.7 & 53.8 & 46.4 \\
69.1 & 50.6 & 61.9 & $59 \cdot 5$ \\
53.5 & 58.6 & 62.9 & $54 \cdot 7$ \\
67.6 & 56.4 & 67.6 & 53.1 \\
53.6 & & 57.6 & \\
60.0 & & 71.8 & \\
\hline
\end{tabular}

type I and type II muscle fibres were compared using the Mann-Whitney $U$ test.

\section{Results}

The results are summarised in Tables 1 and 2 .

\section{Clinical}

All except one patient (No 11) had a long history (2-20 yr) of heavy alcohol intake. Patient 11 had been drinking heavily for only six months. Only one patient (No 7) complained of weakness. Muscle wasting was absent in four patients, mild or moderate in nine and severe in two. Clinically apparent weakness was present in seven cases.

Serum creatine phosphokinase activities showed a slight increase in two patients on admission and in both this returned to normal after a few days in hospital. Abnormal liver function tests were present in 14 patients. Liver biopsy showed micronodular cirrhosis in four patients and fatty infiltration with variable fibrosis in the remainder. No correlations were found between histological changes in the liver and muscle.

\section{MUSCLE MORPHOLOGY}

Light microscopy

Atrophy of fibres and variation in fibre size was clearly seen with histochemical stains (Fig. 1). There

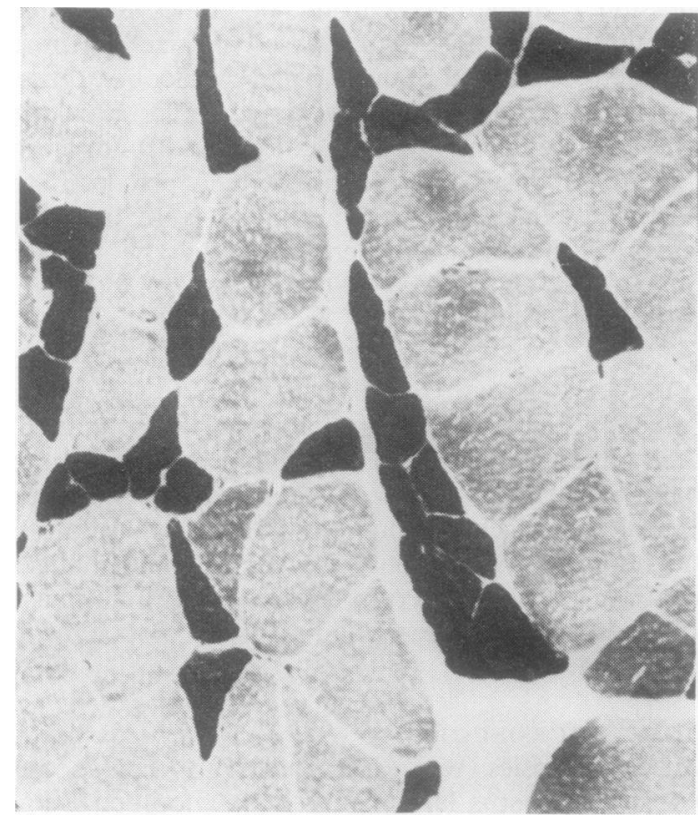

Fig. 1 The type II fibres are angular and atrophied whilst the type I fibres are normal ATP-ase pH 9.4, $\times 280$. 


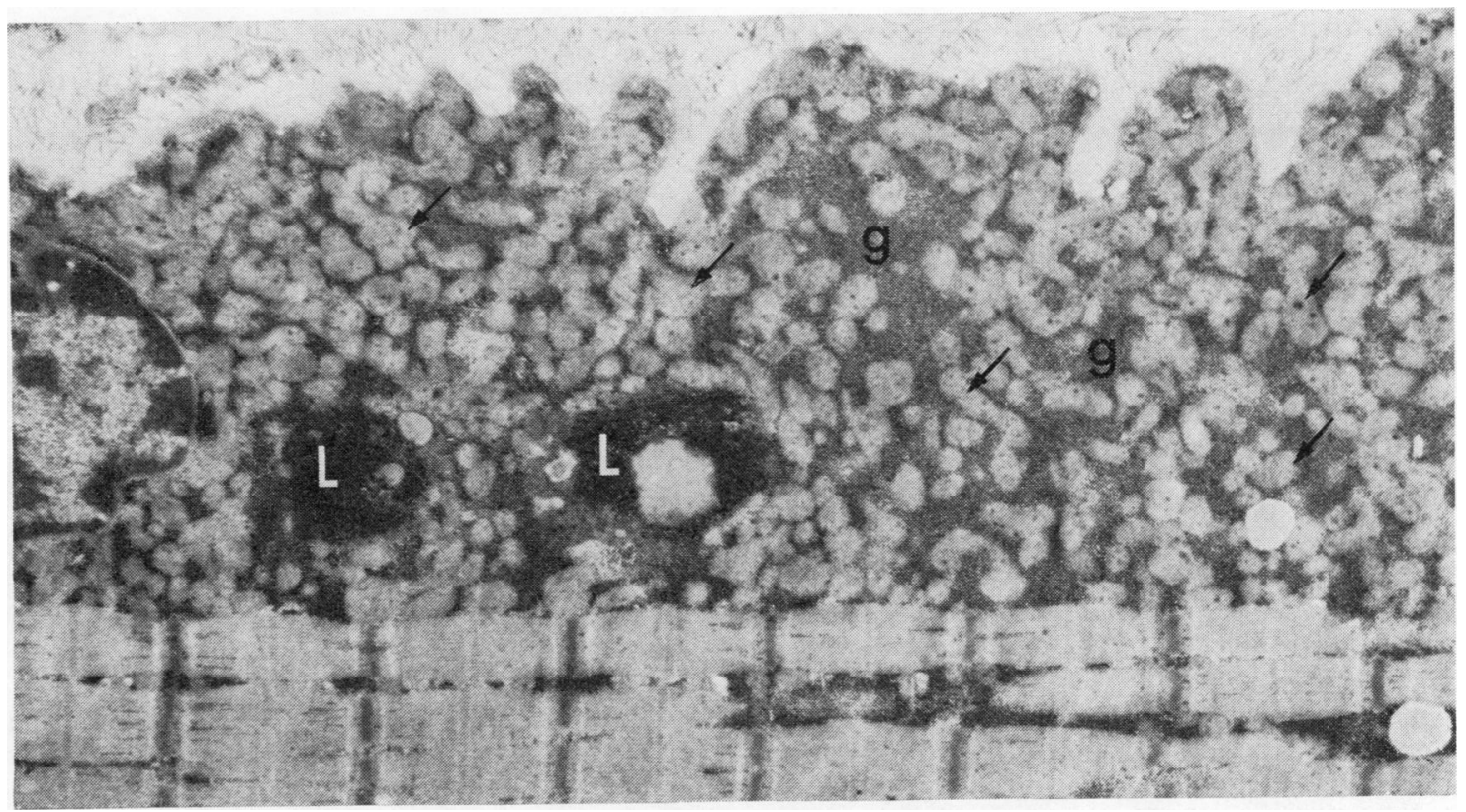

Fig. 2a Longitudinal section of muscle $(\times 10500)$. There is an excess of mitochondria. Between the mitochondria $(\downarrow)$ collections of glycogen $(G)$ and lipid droplets $(L)$ are noted.

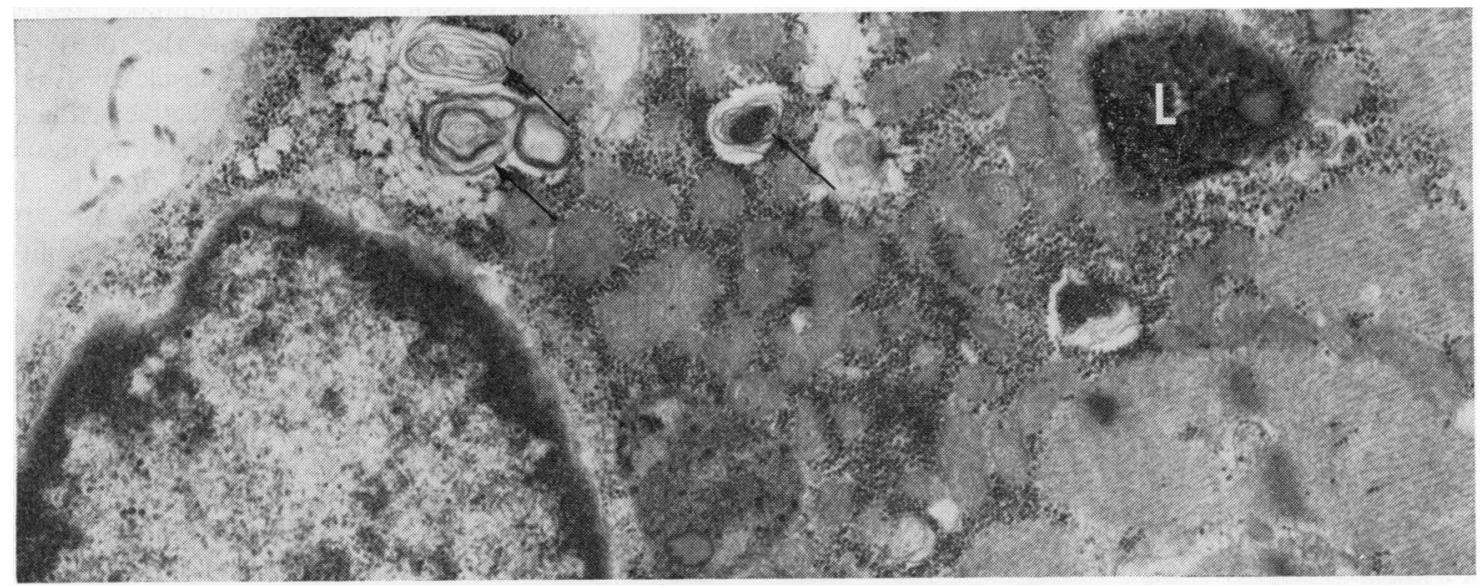

Fig. 2b In addition to the lipid droplets $(L)$ and glycogen granules, membranous bodies $(\uparrow)$ adjacent to the nucleus are seen. $\times 20500$.

was no evidence of fibre degeneration or fibre necrosis. The central nuclear count was within normal limits in each patient. No evidence of fibre type grouping or of denervation was seen. At light microscopic level there was no apparent excess of glycogen or lipid in the muscle fibres. Phosphorylase staining appeared within normal limits and satisfactorily separated fibre types.

\section{Morphometry}

As a group the alcoholic patients showed significant type II atrophy (males p $<0.01$, females $p<0.05$ ) when the median fibre diameters were compared with controls. As individuals all save one patient showed type II atrophy when this was expressed as a weighted score of small fibres. The degree of atrophy varied and was often mild/moderate but in some 


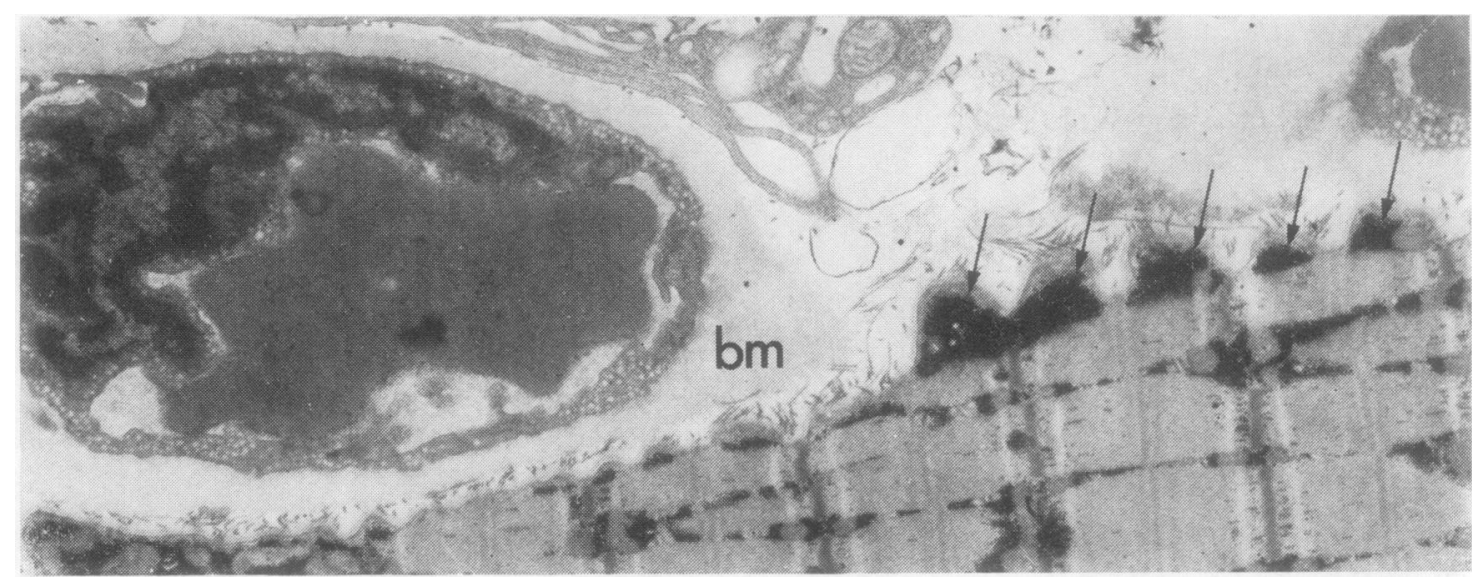

Fig. 2c A capillary with unusually thickened basement membrane $(\mathrm{bm})$ is seen adjacent to a muscle fibre. There are prominent glycogen deposits $(\uparrow \uparrow)$ beneath the sarcolemma and between the myofibrils. $\times 10250$.

patients was gross (Fig. 1). Type I atrophy was not significant as a group change but in three patients there was mild/moderate atrophy when this was individually scored. No hypertrophic fibres were noted.

\section{Electron microscopy}

Each biopsy showed an excess of lipid and free glycogen (Fig. 2) between the myofibrils and immediately below the plasma membrane. An excess of membrane bound glycogen was found in two patients. Atrophic muscle fibres were found in four and in these empty basement membrane folds, disorganised myofibrils and thick z-lines (nemaline rods) were also noted. In seven patients there was a striking homogeneous thickening of the basement membrane of capillaries and in one the capillaries had multiple layers of basement membrane material. No consistent mitochondrial abnormalities were noted. Mitochondria were seen in excess in one patient. Occasional membranous bodies were noted with the fibres.

\section{Discussion}

The occurrence of muscle abnormalities in chronic alcoholism is now well recognised though florid clinical manifestations are uncommon. ${ }^{12}{ }^{4}$ However, despite this recognition there have been few morphological studies of striated muscle in alcoholism. Klinkerfuss et al..$^{5}$ reported random small fibres and minor cytoplasmic architectural changes. Ekbom et al. ${ }^{6}$ described segmental necrosis and regeneration in acute myolysis and atrophy in a chronic syndrome but both these studies were on simple histological examination. Kiessling and his co-workers ${ }^{2}$ utilising histochemical techniques showed diminution in the size of fast twitch glycolytic fibres in eleven patients admitted to hospital for severe alcohol abuse. In a miscellaneous group of patients, Edwards illustrating the use of needle biopsy ${ }^{7}$ described two patients with chronic alcoholism who showed type II atrophy but no other details are given. In our study 15 patients selected on the basis of a daily alcohol intake greates than $80 \mathrm{~g}$ have been studied. Despite the relatively? minor and inconstant evidence of muscle dysfunction by simple subjective and objective clinical assessment and by the lack of increased serum muscle enzymes there is significant atrophy of type II fibres as measured by median fibre diameters. In individual patients there was considerable variability in the degree of atrophy expressed as an atrophy factor but in some patients this was gross. It is noteworthy that the patient who had been drinking heavily for only six months (No 11) showed no fibre atrophy. No other abnormalities were noted at light microscopy but on electron microscopy there was an excess of lipid and free glycogen.

It is not clear whether the effects seen in the muscle of alcoholics are due primarily to alcohol, to its metabolites such as acetaldehyde, or reflect other stigmata of the disease including malnutrition. It is clear, however, that histochemically demonstrable atrophy is present in patients without evidence of wasting or malnutrition. Moreover Rubin $^{8}$ has produced ultrastructural injury in non-alcoholic volunteers subject to one month of ethanol ingestion whilst taking a high protein diet with vitamin and mineral supplements. This was characterised by intracellular oedema, lipid droplets and an excess of glycogen with abnormal mitochondria.

The significance of type II atrophy is uncertain. 
It has been described in patients with osteomalacia, ${ }^{9}$ rheumatoid arthritis, ${ }^{10}$ hypothyroidism, ${ }^{11}$ Cushing's syndrome ${ }^{12}$ and iatrogenic corticosteroid excess. It has been suggested ${ }^{13}$ that type II atrophy results from muscular inactivity and is a non-specific effect. This is unlikely for in immobilised lower limbs preferential type I atrophy is produced. ${ }^{14}$ An alternative view is that type II fibre atrophy may reflect selective metabolic lesions which specifically affects fibres dependent primarily on glycogenolytic pathways for their metabolism and it is noteworthy that in alcoholism and in hypothyroid myopathy an excess of glycogen may be found within the muscle fibres. These end-stage lesions are not identical for other morphological differences may be noted in patients with type II atrophy. Thus, the muscle in hypothyroid patients differs from those in alcoholics by the presence of marked nuclear shift ${ }^{15}$ and more gross deposits of glycogen in the fibres. ${ }^{16}$ This implies a difference either qualitative or quantitative in the biochemical pathways which underlie the lesion. This difference may indeed reflect only a non-specific mechanism but it is open to further metabolic investigation.

\section{References}

1 Perkoff GT. Alcoholic myopathy. Annu Rev Med 1971;22: 125-32.

${ }^{2}$ Kiessling KH, Pilström L, Bylund AC, Piehl K, Saltin B. Effects of chronic ethanol abuse on structure and enzyme activities of skeletal muscle in man. Scand $J$ Clin Lab Invest 1975;35:601-7.

${ }^{3}$ Brooke MH, Engel WK. The histographic analysis of human muscle biopsies with regard to fibre types. I Adult male and female. Neurology (NY) 1969;19:221-33.
+ Ol SJ. Alcoholic myopathy: a critical review. Ala J Med Sci 1972;9:79-95.

${ }^{5}$ Klinkerfuss G, Bleisch V, Dioso MM, Perkoff GT. A spectrum of myopathy associated with alcoholism. II Light and electron microscopic observations. Ann Intern Med 1967;67:493-510.

${ }^{6}$ Ekbom K, Hed R. Kustein L, Aström KE. Muscular affections in chronic alcoholism. Arch Neurol 1964;10: 449-58.

${ }^{7}$ Edwards RHT, Lewis PD, Maunder C, Pearse AGE. Percutaneous muscle biopsy in the diagnosis of muscle diseases. Lancet 1973 ;ii:1070-1.

8 Rubin E. Alcoholic myopathy in heart and skeletal muscle. N Engl J Med 1979;301:28-33.

9 Young A, Brenton DP, Edwards RHT. Analysis of muscle weakness in osteomalacia (abstract). Clinical Science and Molecular Medicine 1978;54:31P.

${ }^{10}$ Edström L, Nordemar R. Differential changes in type I and type II muscle fibres in rheumatoid arthritis: a biopsy study. Scand J Rheumatol 1974;3:155-60.

${ }^{11}$ McKeran RO, Slavin G, Andrews TM, Ward P, Main WGP. Muscle fibre type changes in hypothyroid myopathy. J Clin Pathol 1975;28:659-63.

12 Pleasure DE, Walsh GO, Engel WK. Atrophy of skeletal muscle in patients with Cushing's syndrome. Arch Neurol 1970;22:118-25.

${ }^{13}$ Dubowitz V, Brooke MH. Muscle biopsy: a modern approach. London: WB Saunders, 1973:79.

14 Häggmark T, Brooke MH. Cylinder or mobile cask brace after knee ligament surgery: a clinical analysis and morphologic and enzymatic studies of changes in the quadriceps muscle. Am J Sports Med 1979;7:48-56.

15 McKeran RO, Ward P, Slavin G, Paul EA. Central nuclear counts in muscle fibres before and during treatment in hypothyroid myopathy. J Clin Pathol 1979; 32:229-33.

${ }^{16}$ McKeran RO, Slavin G, Ward P, Paul EA, Main WPG. Hypothyroid myopathy: a clinical and pathological study. J Pathol 1980;132:35-54.

Requests for reprints to: Dr G Slavin, Department of Histopathology, Northwick Park Hospital, Watford Road, Harrow, Middlesex HA1 3UJ, England. 